\title{
Синтез методом молекулярно-пучковой эпитаксии и структурные свойства GaP- и InP-нитевидных нанокристаллов на SiC-подложке с пленкой графена
}

\author{
( Р.Р. Резник ${ }^{1}$, К.П. Котляр ${ }^{2}$, И.В. Илькив ${ }^{2}$, И.П. Сошников ${ }^{2,3,5}$, С.П. Лебедев ${ }^{5}$, А.А. Лебедев ${ }^{5}$, \\ Д.А. Кириленко ${ }^{5}$, П.А. Алексеев ${ }^{5}$, Г.Э. Цырлин ${ }^{1-4}$ \\ ${ }^{1}$ Университет ИТМО, \\ 197101 Санкт-Петербург, Россия \\ ${ }^{2}$ Санкт-Петербургский Академический университет, \\ 194021 Санкт-Петербург, Россия \\ ${ }^{3}$ Институт аналитического приборостроения Российской академии наук, \\ 190103 Санкт-Петербург, Россия \\ ${ }^{4}$ Санкт-Петербургский политехнический университет Петра Великого, \\ 195251 Санкт-Петербург, Россия \\ ${ }_{5}^{5}$ Физико-технический институт им. А.Ф. Иоффе Российской академии наук, \\ 194021 Санкт-Петербург, Россия \\ E-mail: moment92@mail.ru
}

(Получена 25 апреля 2018 г. Принята к печати 7 мая 2018 г.)

\begin{abstract}
Впервые была продемонстрирована принципиальная возможность синтеза GaP- и InP-нитевидных нанокристаллов методом молекулярно-пучковой эпитаксии на подложке карбида кремниям с пленкой графена. InP-нанокристаллы на такой подложке не имеют дефектов упаковки и обладают идеальным кристаллографическим качеством, в то время как $\mathrm{GaP}$ нитевидные кристаллы имеют структурные дефекты типа двойников/перекидок кристаллографических фаз у вершины и основания. Результаты структурных исследований показали, что нитевидные нанокристаллы сформировались в вюрцитной фазе, не типичной для объемных III-V материалов.
\end{abstract}

DOI: 10.21883/FTP.2018.11.46591.13

\section{1. Введение}

Нитевидные нанокристаллы (ННК) III-V полупроводниковых соединений представляют большой интерес как с фундаментальной, так и прикладной точек зрения благодаря их уникальным свойствам. В качестве наиболее важных из них следует указать высокую прочность, большое отношение высоты к диаметру, квазиодномерность в оптоэлектронных спектрах и другие [1-4]. Уникальные свойства ННК обеспечивают перспективность их применения в приборах наноэлектроники (электронные эмиттеры, микрогазоанализаторы, полевые транзисторы, туннельные диоды, одноэлектронные устройства) [5], нанофотоники (светодиоды, лазеры, источники одиночных фотонов) [6,7], наноэлектромеханических системах $[8]$ и солнечной энергетике (фотоэлектрические преобразователи) [9] и др.

В настоящее время для создания приборов на основе ННК используют времязатратные и дорогостоящие методики. В большинстве случаев электрические контакты к ННК формируют с помощью оптической или электронной литографии. Зачастую ННК необходимо предварительно удалить с подложки. Однако, если бы удалось синтезировать нитевидные нанокристаллы сразу на проводящем слое, выступающем в роли контакта, затраты времени и средств на создание приложений значительно сократились бы.

Графен (один монослой графита) в настоящее время является предметом обширных исследований. Высокая подвижность носителей заряда (максимальная подвижность электронов среди всех известных материалов) делает его перспективным материалом для использования в самых различных приложениях, в частности, как будущую основу наноэлектроники [10] и возможную замену кремния в интегральных микросхемах. Благодаря уникальным физическим свойствам графен обладает огромным потенциалом для создания устройств нового поколения, реализующих принципы баллистической электроники, спинтроники, оптоэлектроники, наноплазмоники и других перспективных альтернатив традиционной полупроводниковой электроники [11]. Все вышеперечисленные свойства характеризуют графен как идеальный контакт к ННК. Интегрировать полупроводниковые III-V ННК с графеном позволяет технология синтеза методом молекулярно-пучковой эпитаксии (МПЭ) на поверхностях, активированных каплями катализатора роста.

В данной работе впервые продемонстрирована принципиальная возможность синтеза методом МПЭ $\mathrm{GaP}$ и InP НHК на подложке карбида кремния $(\mathrm{SiC})$ c пленкой графена на поверхности и изучены структурные свойства выращенных ННК.

\section{2. Экспериментальные методы}

Для получения пленок графена использовался метод термического разложения поверхности $\mathrm{SiC}$, описанный в работе [12]. В отличие от работ $[13,14]$, где рост 

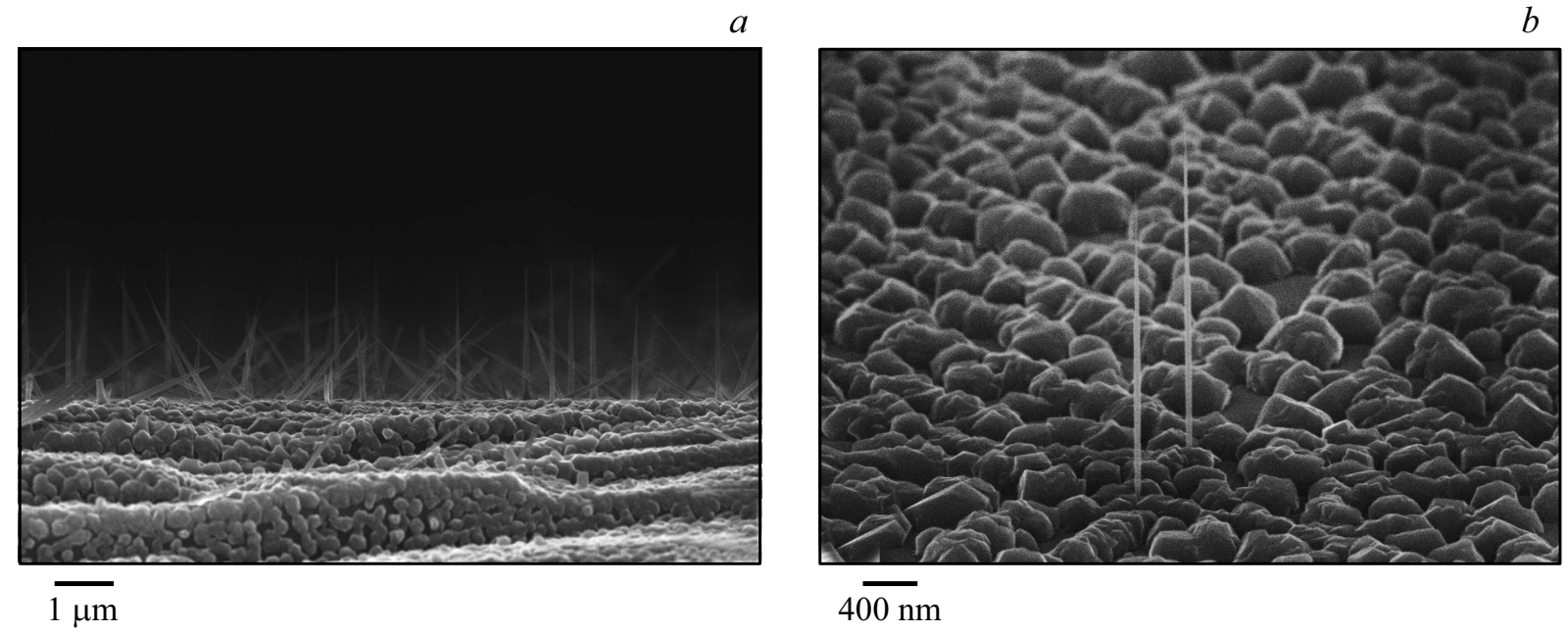

Рис. 1. Типичные РЭМ изображения массивов ННК, выращенных на подложке $\mathrm{SiC}$ с пленкой графена: $a-\mathrm{GaP}$ HНК, $b-$ InP HHK.

графена проходил в высоком вакууме, в данной работе использовалась усовершенствованная технология роста в среде инертного газа (аргона), позволяющая более точно контролировать процесс сублимации компонентов карбида кремния. Как следствие, с помощью подбора оптимальных технологических параметров можно с высокой точностью контролировать как процесс роста графеновой пленки, так и однородность покрытия подложки графеном.

В качестве подложки использовались высокоомные пластины $\mathrm{SiC}$ политипа $6 H$ с ориентацией $(0001) \pm 0.25^{\circ}$ (Si-грань). Рост графена производился в графитовом тигле, нагреваемом индуктивным методом с помощью высокочастотного генератора. Для определения оптимальных условий получения графена осуществлялось варьирование основных технологических параметров: температура роста изменялась от 1750 до $1900^{\circ} \mathrm{C}$, время роста — от 10 до 30 мин, давление аргона в ростовой камере - от 600 до 800 Торр, скорость нагрева образца - от 100 до $350^{\circ} \mathrm{C} / \mathrm{Mин.}$

Эксперименты по росту GaP и InP HНК на описанных выше подложках проводились с помощью установки молекулярно-пучковой эпитаксии Compact21 фирмы Riber, оснащенной отдельной камерой металлизации с эффузионным источником золота, транспортировать из которой образец в ростовую камеру, оснащенную эффузионными источниками галлия, индия и фосфора, можно без нарушения условий вакуума. Процедура предварительной очистки и формирования капель-катализаторов была одинакова для обоих образцов. На первом этапе загруженная в камеру металлизации подложка нагревалась до $500^{\circ} \mathrm{C}$ для термической очистки. Давление в камере в этот момент составляло $7 \cdot 10^{-8}$ Торр. Затем при той же температуре напыляли тонкий слой золота, после чего перед охлаждением подложки выдерживали паузу в течение минуты для формирования нанометровых капель золота на поверхности для последующего роста ННК. После транспортировки подложки со сформированными каплями катализатора в ростовую камеру без нарушения условий вакуума подложка нагревалась до ростовой температуры. В случае синтеза GaP НHК она составила $500^{\circ} \mathrm{C}$, в случае InP ННК $-250^{\circ} \mathrm{C}$. После стабилизации температуры подложки открывались заслонки соответствующих материалов, и начинался рост ННК. Поток галлия при синтезе GaP HНК соответствовал скорости роста планарного слоя GaAs $2.8 \AA /$ c. В случае синтеза InP ННК поток In на поверхность подложки соответствовал скорости роста двумерного слоя $0.4 \mathrm{MC} / \mathrm{c}$. Время роста обеих структур составило 15 мин.

Для исследования поверхности во время проведения ростовых экспериментов (in situ) использовался метод дифракции быстрых электронов на отражение (ДБЭО). По изменениям ДБЭО картин было видно, что формирование нитевидных нанокристаллов начиналось уже после 60 с роста.

Исследования структурных свойств синтезированных структур проводились методами растровой электронной микроскопии (РЭМ) на микроскопе Supra25 фирмы Zeiss и трансмиссионной электронной микроскопии (ТЭМ) на микроскопе JEOL 2100.

\section{3. Результаты и обсуждение}

На рис. 1, $a$ и $b$ приведены типичные РЭМ изображения выращенных массивов GaP и InP ННК на графене соответственно. Из рис. 1, $a$ видно, что GaP ННК сформировались преимущественно в направлении (111), а их диаметр составил 80 нм у основания и 15 нм у вершины ННК. Массив GaP нанокристаллов на графене обладает средней поверхностной плотностью $3 \cdot 10^{8} \mathrm{~cm}^{-2}$, в то время как средняя высота ННК составляет 3 мк.

Результаты исследований морфологических свойств выращенных массивов InP ННК на графене, приведенные на рис. $1, b$, показали, что, как и в случае GaP НHК, InP-нанокристаллы сформировались преимущественно в 
$a$

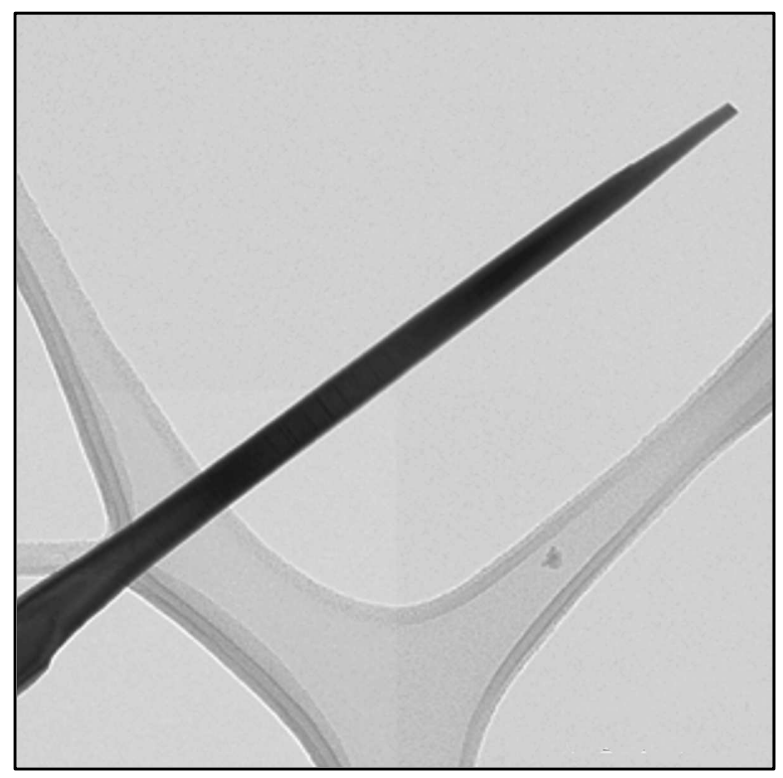

$200 \mathrm{~nm}$ $b$

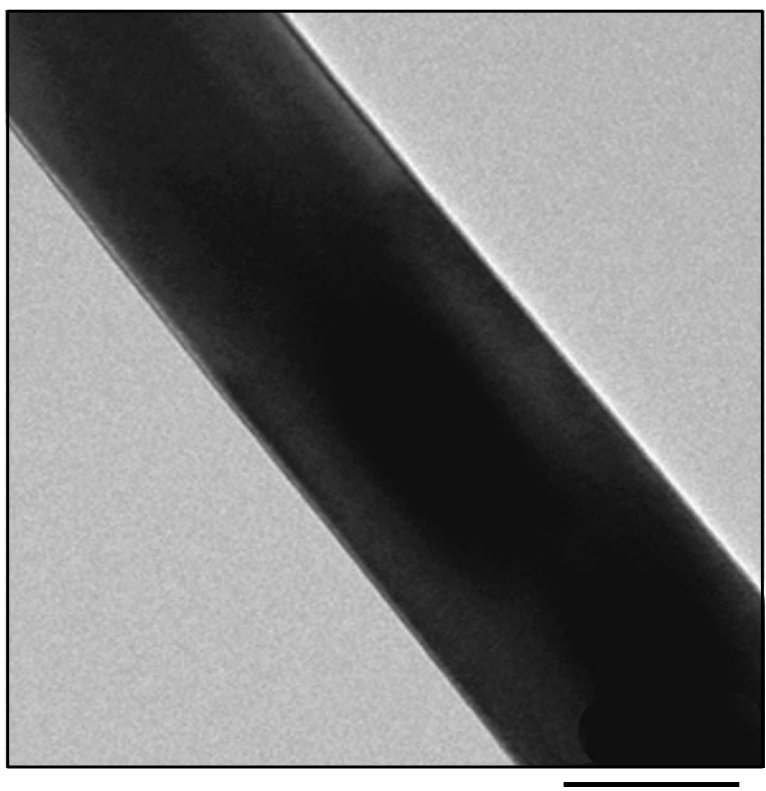

$50 \mathrm{~nm}$

Рис. 2. ПЭМ изображения $\mathrm{GaP}$ ННК, выращенного на подложке $\mathrm{SiC}$ с пленкой графена: вершина ННК $(a)$, середина ННК $(b)$.

a

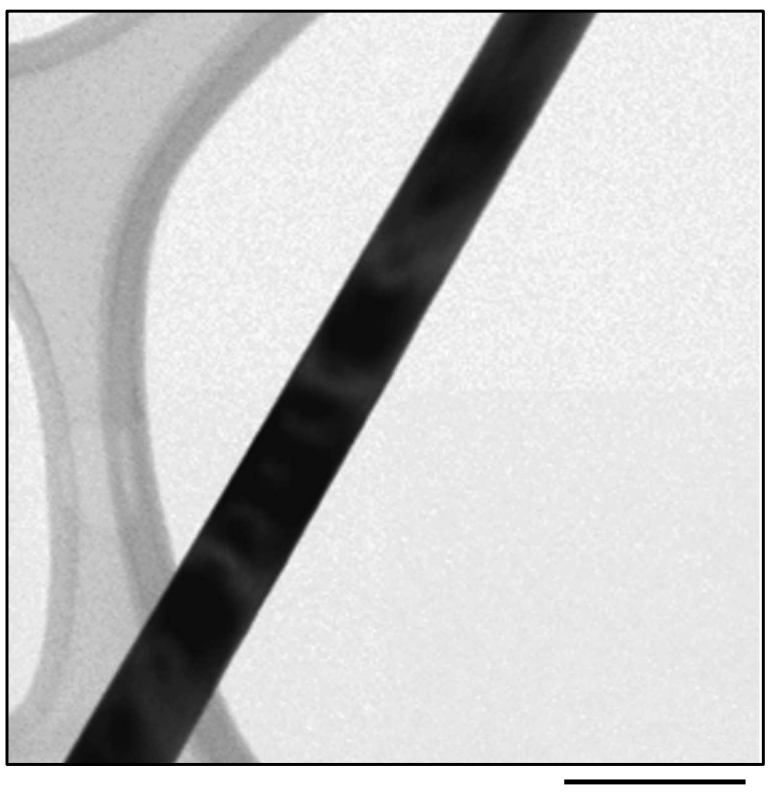

$100 \mathrm{~nm}$

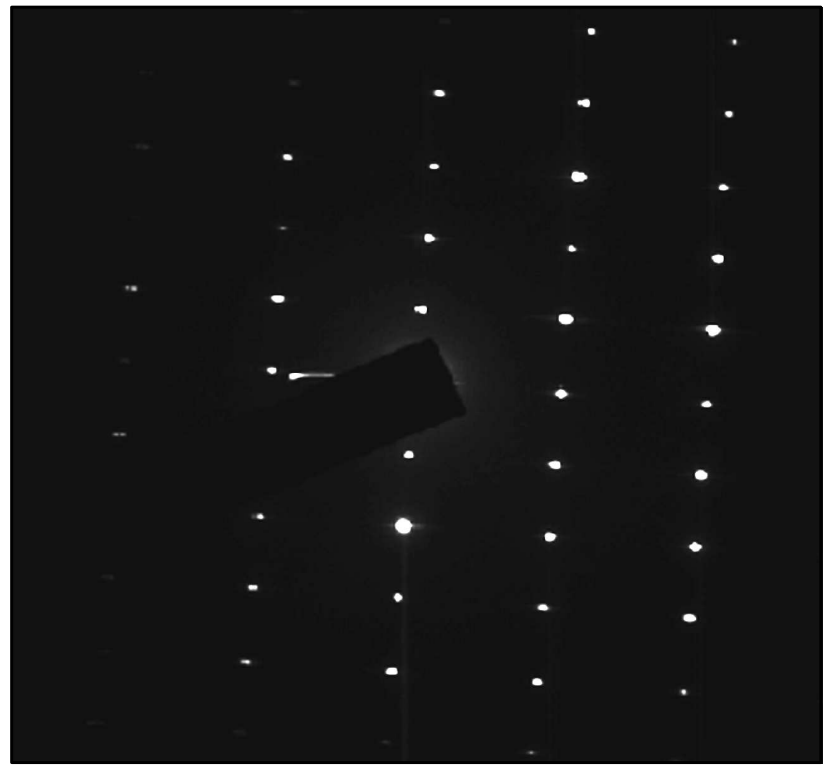

Рис. 3. ПЭМ изображение $\mathrm{InP}$ ННК, выращенного на подложке $\mathrm{SiC}$ с пленкой графена $(a)$, и картина электронной дифракции $(b)$.

направлении (111), и их средняя высота составляет 3 мк. Однако массивы таких ННК обладают меньшей поверхностной плотностью - порядка $1 \cdot 10^{7} \mathrm{~cm}^{-2}$. Кроме того, выращенные InP ННК обладают меньшим диаметром: 50 нм в основании и 10 нм у вершины. Вероятно, это связано с тем, что рассогласование по постоянным решетки между InP и графеном больше, чем между $\mathrm{GaP}$ и графеном [15]. Таким образом, исследования морфологических свойств методом РЭМ подтвердили возможность реализации МПЭ роста $\mathrm{GaP}$ и $\mathrm{InP}$ НHК на таких подложках.

На рис. 2 и 3 приведены результаты исследований структурных свойств с помощью метода ТЭМ GaP ННК и InP ННК соответственно. На рис. 2, $a$ и $b$ показаны типичные ТЭМ изображения $\mathrm{GaP}$ ННК, выращенного на графене. Картины локальной дифракции 
показали, что $\mathrm{GaP}$ ННК синтезировались в вюрцитной фазе. В нижней и верхней частях ННК присутствуют дефекты упаковки, отсутствующие в центральной части, что также проявлялось на картинах электронной дифракции.

На рис. 3, $a$ и $b$ представлены типичное ТЭМ изображение InP ННК, выращенного на графене, и картина локальной дифракции от того же ННК. Из рисунка видно, что, как и в случае $\mathrm{GaP}$ ННК, они обладают вюрцитной фазой. Однако стоит отметить, что в InP ННК на графене не имеют протяженных дефектов и дефектов упаковки типа двойников. Таким образом, InP ННК, выращенные на графене, обладают чистой вюрцитной фазой.

\section{4. Заключение}

В результате работы нами впервые была продемонстрирована принципиальная возможность синтеза $\mathrm{GaP}$ и InP ННК методом МПЭ на подложке $\mathrm{SiC}$ пленкой графена. Результаты структурных исследований выращенных ННК показали, что ННК сформировались в вюрцитной фазе. InP ННК на такой подложке не имеют дефектов упаковки и обладают идеальным кристаллографическим качеством.

Синтез образцов был выполнен при финансовой поддержке Министерства образования и науки Российской Федерации (в рамках выполнения государственного задания № 16.2483.2017/4.6). Исследования структурных свойств ННК были выполнены при финансовой поддержке гранта РНФ № 14-12-00393.

\section{Список литературы}

[1] M.P. Persson, H.Q. Xu. Appl. Phys. Lett., 81, 1309 (2002).

[2] M.S. Gudiksen, L.J. Lauhon, J. Wang, D.C. Smith, C.M. Lieber. Nature, 415, 617 (2002).

[3] K. Hiruma, M. Yazawa, T. Katsuyama, K. Ogawa, K. Haraguchi, M. Koguchi, H. Kakibayashi. J. Appl. Phys., 77, 447 (1995).

[4] K. Haraguchi, T. Katsuyama, K. Hiruma. J. Appl. Phys., 75, 4220 (1994).

[5] T. Bryllert, L.-E. Wernersson, L.E. Fröberg, L. Samuelson. IEEE Electron. Dev. Lett., 27, 323 (2006).

[6] S. Hirano, N. Takeuchi, S. Shimada, K. Masuya, K. Ibe, H. Tsunakawa, M. Kuwabara. J. Appl. Phys., 98, 305 (2005).

[7] N.D. Zakharov, V.G. Talalaev, P. Werner, A.A. Tonkikh, G.E. Cirlin. Appl. Phys. Lett., 83, 3084 (2003).

[8] S. Perisanu, V. Gouttenoire, P. Vincent, A. Ayari, M. Choueib, M. Bechelany, D. Cornu, S.T. Purcell. Phys. Rev. B, 77, 434 (2008).

[9] L. Tsakalakos, J. Balch, J. Fronheiser, B.A. Korevaar, O. Sulima, J. Rand. Appl. Phys. Lett., 91, 117 (2007).

[10] Zh. Chen, Yu-M. Lin, M.J. Rooks, Ph. Avourisl. Physica E: Low-Dim. Systems and Nanostructures, 40, 228 (2007).
[11] A.C. Ferrari, F. Bonaccorso, V. Fal'ko, K.S. Novoselov, S. Roche, P. Boggild, S. Borini, F.H. Koppens, V. Palermo, N. Pugno, J.A. Gazzido, R. Sordan, A. Bianco, L. Ballerini, M. Prato, E. Lidorikis, J. Kivioja, C. Marinelli, T. Ryhänen, A. Morpurgo, J.N. Coleman, V. Nicolosi, L. Colombo, A. Fert, M. Garcia-Hernandez. Nanoscale, 7, 4598 (2015).

[12] В.Ю. Давыдов, Д.Ю. Усачев, С.П. Лебедев, А.Н. Смирнов, В.С. Левицкий, И.А. Елисеев, П.А. Алексеев, М.С. Дунаевский, О.Ю. Вилков, А.Г. Рыбкин, А.А. Лебедев. ФТП, 51, 1116 (2017).

[13] Н.В. Агринская, В.А. Березовец, В.И. Козуб, И.С. Котоусова, А.А. Лебедев, С.П. Лебедев, А.А. Ситникова. ФТП, 47, 267 (2013).

[14] А.А. Лебедев, С.П. Лебедев, С.Н. Новиков, В.Ю. Давыдов, А.Н. Смирнов, Д.П. Литвин, Ю.Н. Макаров, В.С. Левицкий. ЖТФ, 86, 135 (2016).

[15] G.E. Cirlin, V.G. Dubrovskii, I.P. Soshnikov, N.V. Sibirev, Yu.B. Samsonenko, A.D. Bouravleuv, J.C. Harmand, F. Glas. Phys. Status Solidi RRL, 3-4, 112 (2009).

Редактор Г.А. Оганесян

\section{MBE growth and structural properties of GaP and InP nanowires SiC substrate with graphene layer}

R.R. Reznik ${ }^{1}$, K.P. Kotlyar ${ }^{2}$, I.V. Ilkiv', I.P. Soshnikov 2,3,5, S.P. Lebedev ${ }^{5}$, A.A. Lebedev ${ }^{5}$, D.A. Kirilenko ${ }^{5}$, P.A. Alexeev ${ }^{5}$, G.E. Cirlin ${ }^{1-4}$

${ }^{1}$ ITMO University, 197101 St. Petersburg, Russia

${ }^{2}$ St. Petersburg Academic University,

Russian Academy of Sciences,

194021 St. Petersburg, Russia

${ }^{3}$ Institute for Analytical Instrumentation,

Russian Academy of Sciences,

190103 St. Petersburg, Russia

${ }^{4}$ Peter the Great St. Petersburg Polytechnic University, 195251 St. Petersburg, Russia

${ }^{5}$ loffe Institute,

194021 St. Petersburg, Russia

Abstract A possibility of $\mathrm{GaP}$ and $\mathrm{InP}$ nanowires MBE growth on $\mathrm{SiC}$ substrate with graphene layer has been demonstrated for the first time. The results of structural measurements of grown nanowires have shown that nanowires were formed in the wurtzite phase. InP nanowires on such a substrates have no packaging defects and have an ideal crystallographic quality. 